\title{
Impactos socioeconômicos do Programa Nacional de Alimentação Escolar na agricultura familiar de Santa Catarina
}

\author{
Socioeconomic impacts of the National School Feeding \\ Program on family farming in Santa Catarina
}

\author{
Lilian de Pellegrini Elias ${ }^{1}$ (D), Walter Belik ${ }^{1}$ (D), Marcelo Pereira da Cunha ${ }^{1}$ (D) e
} Joaquim Jose Martins Guilhoto ${ }^{2 *}$

Resumo: O Programa Nacional de Alimentação Escolar (PNAE), responsável por atender todas as escolas públicas brasileiras, passou, em 2009, a contar com a obrigatoriedade de empregar ao menos $30 \%$ do recurso federal em compras diretas de agricultores familiares. A obrigatoriedade tem como objetivo proporcionar melhor alimentação e concomitante desenvolvimento rural a partir do fortalecimento da agricultura familiar. Tais propostas estão sendo concretizadas, mas ainda estão distantes de seu potencial. Neste sentido, o presente artigo, tendo o estado de Santa Catarina como objeto de estudo, trata de identificar fragilidades e propor adequações no PNAE levando-se em conta os aspectos da operacionalização e dos efeitos socioeconômicos da política pública. Os métodos utilizados foram um levantamento qualitativo feito a partir de 98 entrevistas em 31 municípios de Santa Catarina e uma análise quantitativa, tendo como instrumento para avaliação de impacto a matriz insumo-produto. As entrevistas contemplaram agricultores familiares, responsáveis pela execução do PNAE e técnicos que apoiam a agricultura familiar. Já o modelo de insumo-produto permitiu avaliar os efeitos socioeconômicos da implementação da política. Os resultados apresentam evidências de que políticas de comercialização, como o PNAE, são uma forma de promoção do desenvolvimento rural, desde que constantemente reestruturadas para contemplar a heterogeneidade e a pulverização da agricultura familiar no território.

Palavras-chave: desenvolvimento rural, agricultura familiar, PNAE, alimentação escolar, análise de insumo-produto.

\footnotetext{
* O conteúdo desta publicação expressa a visão deste autor e não necessariamente representa a visão da OCDE ou dos seus países membros.

Data de submissão: 30 de outubro de 2016. Data de aceite: 27 de maio de 2018.

1. Universidade Estadual de Campinas (UNICAMP), Campinas (SP), Brasil. E-mail: lilianpellegrini@gmail.com; walterbelik@gmail.com; marcelocunha@eco.unicamp.br

2. Organisation for Economic Co-operation and Development, Paris, France. E-mail: joaquim.guilhoto@oecd.org
} 
Abstract: The Brazilian School Feeding Program, responsible to provide all Brazilian public schools, started to have the obligation by law to designate at least 30\% of the federal resource with family farmer products in 2009. The objectives of the law are generating higher quality of school feeding and strengthening family farmers. These objectives are being achieved, but are still far from its potential. In this context, the paper intends to identify weaknesses and propose adequacies in the PNAE taking into account the aspects of the operationalization and socioeconomic effects of public policy. The paper object is the state of Santa Catarina. The analysis is divided in two parts. The first one is an evaluation of the operationalization and the effects of the policy in 31 municipalities through interviews with farmers, responsible for implementing the PNAE and rural extension agents involved with the PNAE. The second one is a socio-economic analysis from an inter-regional input-output model about the effect of the school food shopping. The results show good evidence that market policies, such as PNAE, are a way of promoting rural development since they are constantly restructured to contemplate size, heterogeneity and scattering distribution of family farming.

Key-words: rural development, family farm, PNAE, school feeding, input-output analysis.

Classificação JEL: Q22, R5.

\section{Introdução}

Nas últimas décadas, a agricultura familiar passou a ser identificada como meio fundamental de organização das produções agropecuárias e de desenvolvimento rural. A razão permeia sua importante contribuição para a segurança alimentar e nutricional, geração de renda no campo e das economias locais, preservação dos alimentos tradicionais e da agrobiodiversidade. Esse reconhecimento ganhou solidez com o lançamento do "Ano Internacional da Agricultura Familiar", em 2014, pela Organização das Nações Unidas para a Alimentação e a Agricultura (Food and Agriculture Organization, 2014).

No Brasil, este movimento foi anterior: ainda na década de 1990 a agricultura familiar ganha status de categoria social e política (Grisa \& Schneider, 2015; Schneider, 2010). Neste processo, o Estado criou o Programa Nacional de Fortalecimento da Agricultura Familiar (Pronaf), possibilitando acesso ao crédito e inserção nos mercados; e a Lei da Agricultura Familiar (n. 11.326, 24 de julho de 2006) abrindo espaço para inserir a agricultura familiar em outras áreas de atuação do Estado. Tais transformações permitiram a convergência entre agricultura familiar, educação e segurança alimentar, resultando na criação, em 2009, da lei n. 11.947, que tornou obrigatório o uso de $30 \%$ dos recursos federais destinados para a alimentação escolar para compras da agricultura familiar, priorizando fornecedores locais (Fundo Nacional de Desenvolvimento da Educação, 2017).

Este redirecionamento de parte do recurso para compras diretas de agricultores familiares é o tema discutido neste artigo. A hipótese é a de que o PNAE, ao criar um "mercado potencial" para o fortalecimento da agricultura familiar, pode gerar efeitos econômicos aos agricultores atingidos. O objetivo é analisar a operacionalização da política, expor seu potencial, identificar as dificuldades e propor ações para o seu aprimoramento. O método, desenvolvido a partir de análise de dados secundários, primários e da análise de insumo-produto, permite atingir o objetivo e testar a hipótese.

A pesquisa foi feita ao longo de 2015, quando completa seis anos de vigência da lei que estabeleceu o atual sistema de compras institucionais. O objeto de estudo é o estado de Santa Catarina, localizado na região sul do Brasil. A agricultura catarinense se destaca por ser majoritariamente familiar: esse setor é responsável por $58 \%$ da área, $92 \%$ dos estabelecimentos e $68 \%$ da renda total em Santa Catarina (Instituto Brasileiro de Geografia e Estatística, 2006). Destaca-se também pela ampla heterogeneidade na distribuição da renda e por ter a maior renda média da agricultura familiar por hectare e por estabelecimento do Brasil, sendo que 17\% desses agricultores são pouco integrados ao mercado e têm renda igual ou abaixo do custo de oportunidade com renda média anual de R 1.297 (Instituto Brasileiro de Geografia e Estatística, 2006). Os dois fatores (ampla presença de agricultura familiar e heterogeneidade na distribuição de renda entre agricultores familiares) expõem um potencial de aproveitamento da política pública.

O que diferencia este estudo dos trabalhos baseados em informações qualitativas no campo das compras de agricultura familiar pelo PNAE (Corá \& Belik, 
2012; Fornazier, 2014) é a compatibilização de análise qualitativa e análise socioeconômica quantitativa para abordar uma unidade federativa. Pesquisas, artigos, dissertações e teses (Baccarin et al., 2017; Costa et al., 2015; Fornazier, 2014; Mossmann et al., 2017; Silva, 2012; Triches, 2010) têm mostrado benefícios trazidos pela nova legislação e a necessidade de mais assistência, apoio técnico e articulação intersetorial, bem como maior articulação entre todos os agentes envolvidos. Porém, a investigação sobre os reais impactos e factibilidade de expansão em amplitude e profundidade ainda não havia sido explorada. Assim, o presente texto tem o intuito de contribuir para suprir esta lacuna.

Além desta introdução, o artigo conta com fundamentação teórica; descrição da metodologia; análise do PNAE a partir da pesquisa empírica e de matriz insumo-produto em Santa Catarina e considerações finais.

\section{Agricultura familiar e desenvolvimento rural}

Schejtman \& Berdegué (2004) evidenciam que a permanência da pobreza rural e da vulnerabilidade dos agricultores familiares significa o fracasso do desenvolvimento; sendo o apoio à agricultura familiar central tanto na revisão do arcabouço teórico do desenvolvimento rural quanto da atuação do Estado. O Banco Mundial, por sua vez, assume que a agricultura familiar tem papel fundamental na produção e geração de renda; portanto, no combate à pobreza e no fomento à segurança alimentar; principalmente em regiões menos desenvolvidas - onde três em cada quatro pessoas que trabalham e moram na zona rural são pobres e dependem direta ou indiretamente da agricultura para a sua subsistência (World Bank, 2008).

No Brasil, a criação de políticas públicas para a agricultura familiar resultou da inflexão no debate sobre o tema ocorrida na década de 1990. Nas décadas precedentes ocorrera o aprofundamento do direcionamento de ação do Estado para o processo de modernização ("Revolução Verde") que, junto da abertura e instabilidade econômica, preteriram a inserção produtiva da agricultura familiar (Grisa \& Schneider, 2015) e criaram um cenário de ampliação da pobreza e vulnerabilidade dos agricultores no campo. Este cenário gerou pressão de atores sociais para redirecionar políticas de desenvolvimento rural para sustentabilidade, meio ambiente e para o fomento da agricultura familiar como setor estratégico - não mais marginal. A agricultura familiar conquista espaço e passa a demandar sua inserção nos mercados.

No entanto, consolidar a produção familiar e local como uma alternativa de produção de alimentos pressupõe gerar uma profunda ruptura (Friedmann, 2000; McMichael, 2009; Van Der Ploeg, 2011, 2008). Este movimento depende de que a sociedade civil, o Estado, os pesquisadores e demais atores sociais identifiquem na agricultura familiar uma forma de organização da produção que contribui para a resolução de problemas ambientais, sociais e econômicos - por serem capazes de equilibrar o interesse individual (agricultor e consumidor) com o coletivo (desenvolvimento rural, local, econômico e social). Nesse sentido, uma resposta é a criação de novos espaços que a agricultura familiar possa ocupar, através da criação de circuitos de comercialização que reforce a demanda por produtos tradicionais e locais (Van Der Ploeg, 2008; Wilkinson, 2008).

A criação de novos espaços e a ruptura nos mercados para abrir espaço para a agricultura familiar encontra no Estado uma forte possibilidade de suporte. A demanda pública por alimentos se apresenta como elemento-chave para o desenvolvimento rural e segurança alimentar (Sonnino et al., 2014, p. 5). No passado, as compras governamentais não faziam parte do elenco de políticas voltadas especificamente para o desenvolvimento rural mesmo que o reforço econômico dado pelo gasto público já fosse parte da ação dos Estados desde a primeira metade do século XX a partir do receituário keynesiano, também no Brasil (Belik \& Fornazier, 2016).

No Brasil, políticas públicas cujo escopo inclui aquisição de produtos agropecuários oriundos das unidades familiares de produção ${ }^{1}$ são destinadas para propriedades agrícolas que se enquadram no âmbito do Programa Nacional de Fortalecimento da Agricultura Familiar (Pronaf)². O primeiro programa voltado para

1 Sem abrir mão de rígido controle sanitário e da qualidade dos produtos e sem superar preços praticados nos mercados locais e regionais, a forma de aquisição de alimentos deixa de ser licitação para ser feita através de Chamadas Públicas. Essa mudança tem o objetivo de viabilizar a ampliação das compras diretas de produtos da agricultura familiar (Fundo Nacional de Desenvolvimento da Educação, 2017).

2 A definição legal da categoria Agricultura Familiar ocorre apenas em 2006, a partir da lei n. 11.326, de 24 de julho de 2006 (Brasil, 2006). 
essa clientela e com este objetivo teve início em 2003, sendo denominado Programa de Aquisição de Alimentos (PAA) $^{3}$; em seguida, em 2009, surgiu a lei que torna obrigatória que parte do recurso federal do Programa Nacional de Alimentação Escolar (PNAE) seja destinado a compras diretas da agricultura familiar. Em 2015, todos os órgãos públicos federais passam a ter que destinar $30 \%$ do recurso para compras de produtos da agricultura familiar de acordo com o decreto n. 8.473, de 22 de junho de 2015 (Brasil, 2015).

O incentivo às compras de alimentos de agricultores de produção familiar, como forma de garantir mercados, foi concebido para estimular e fortalecer a agricultura familiar brasileira, especialmente agricultores com pequena produção e que se localizam à margem dos mercados alimentares. Considera-se que estes agricultores possuem grande potencial de transformação da realidade rural e da segurança alimentar e nutricional. O pano de fundo do funcionamento deste tipo de política é comprovar que, caso a agricultura familiar consiga se organizar para atender um grande mercado, seria capaz de suprir parte da necessidade alimentar da população e paralelamente desenvolveria o meio rural.

Apenas no âmbito da política discutida neste artigo, alimentação escolar (PNAE), o Estado tornou obrigatório o direcionamento de pelo menos $\mathrm{R} \$ 1,11$ bilhão de Reais ${ }^{4}$ em $2014-30 \%$ do valor total disponibilizado pelo governo federal para compra de alimentação escolar, que soma R\$3,7 bilhões - para compras de produtos da agricultura familiar.

\subsection{O Programa Nacional de Alimentação Escolar}

O PNAE teve início em 1955 como "Campanha de Merenda Escolar", programa público financiado pelo Ministério da Educação e com alcance limitado a algumas escolas do Rio de Janeiro. A iniciativa toma corpo e

3 Instituído pela lei n. 10.696, de 02 de julho de 2003, e viabilizado a partir de recurso do Fundo de Combate e Erradicação da Pobreza, criado pela Lei Complementar n. 111 de 2001 (Brasil, 2003).

4 O recurso disponibilizado pelo governo federal para o PNAE em 2014 foi de R\$ 3,7 bilhões; portanto, o recurso determinado por lei para ser destinado para a agricultura familiar, ou seja, os $30 \%$, somam $\mathrm{R} \$ 1,11$ bilhão. O valor efetivamente destinado para a compra de produtos da agricultura familiar no mesmo ano foi de R\$ 682 milhões (Fundo Nacional de Desenvolvimento da Educação, 2017). amplia os horizontes com a Constituição de 1988, que estabelece a obrigatoriedade para o fornecimento de alimentação escolar para o ensino fundamental. Nos anos 90 se dá a descentralização das compras e a emergência da gestão municipal ou, alternativamente, escolarizada, dos recursos repassados pelo Ministério da Educação. Nesse mesmo período são introduzidas diretrizes referentes à qualidade da alimentação e, nesse sentido, se estabelece que $70 \%$ dos gêneros adquiridos devem ser "básicos" - em outras palavras, não industrializados -, e que a refeição servida aos estudantes deveria cobrir ao menos $15 \%$ das necessidades nutricionais diárias. Mais adiante, a legislação nos anos 2000 amplia para 20\% a cobertura das necessidades nutricionais dos estudantes, exige a supervisão de um profissional de nutrição na preparação dos cardápios, estabelece limites para a ingestão de sódio e também limites para inserção de industrializados na alimentação escolar. Essa legislação mais restritiva, por sua vez, abriu espaço para uma ação direta estabelecida na lei 1.047/ 2009 reforçando os vínculos entre a administração municipal e os produtores locais.

Os objetivos do PNAE de melhoria na qualidade e diversidade alimentar, impacto na sustentabilidade e proteção ambiental e desenvolvimento rural a partir do fortalecimento da agricultura familiar estão exigindo um enorme esforço por parte dos organismos de gestão municipal e dos próprios produtores. Por um lado, os gestores municipais tiveram que adaptar as suas estruturas para o lançamento de uma modalidade nova de licitação consubstanciada nas "chamadas públicas para compra de alimentos da agricultura familiar". Por outro lado, produtores tiveram que formalizar suas atividades e atender exigências de qualidade, embalagem e apresentação que não eram rotineiras.

Porém, o direcionamento do PNAE para a agricultura familiar pode vir a significar um primeiro passo para gerar maior proximidade entre agricultor e consumidor, permitindo qualidade e diversidade alimentar e, ao mesmo tempo, promovendo a permanência e melhorias de renda ao agricultor familiar. Essa política tem potencial de transpor o âmbito institucional e transformar hábitos alimentares em direção à uma dieta de melhor qualidade, ao mesmo tempo que, pelo lado da oferta, promove-se uma estruturação produtiva dos agricultores, garantindo sua inserção nos mercados.

Em Santa Catarina, os alunos de escolas públicas representam $90 \%$ do total dos alunos presenciais do ensino fundamental e médio e $81 \%$ do total dos alunos de creches e pré-escolas - 1,3 milhão de alunos - no 
Figura 1. Emprego dos recursos do FNDE em Santa Catarina (milhões de reais)

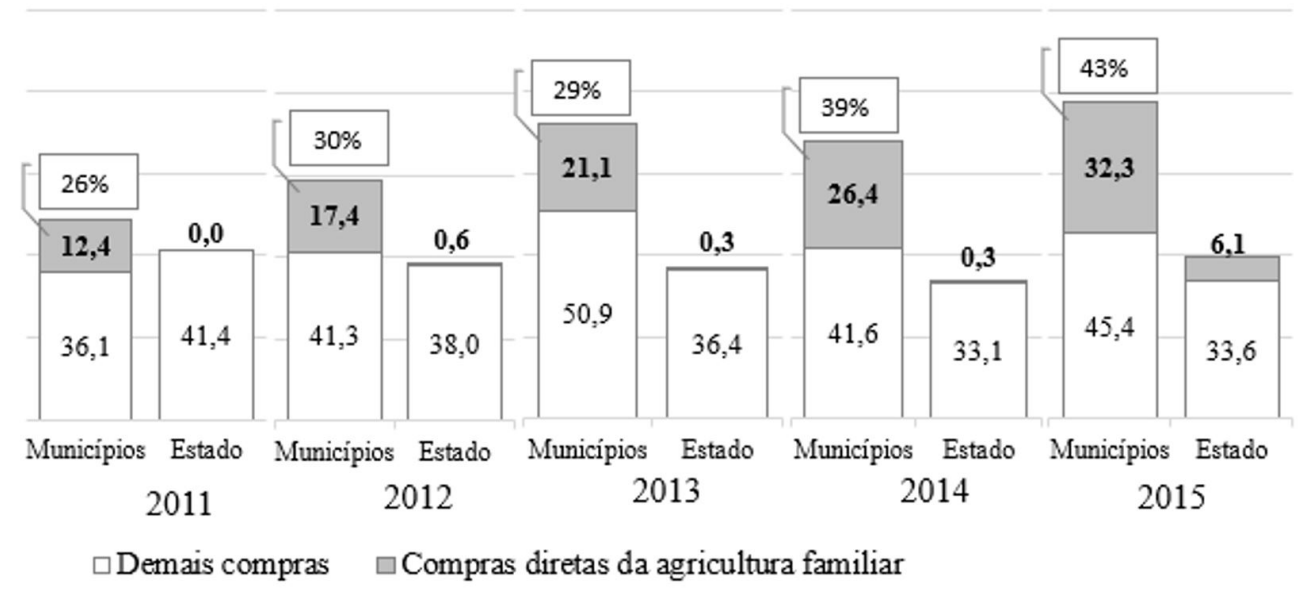

Fonte: FNDE (Fundo Nacional de Desenvolvimento da Educação, 2017).

Brasil, são 90\% do total dos alunos, equivalente a um quinto da população ${ }^{5}$. Considerando-se que alimentação escolar é direito de todos os estudantes de escola pública, a maioria das crianças e adolescentes catarinenses é beneficiada pelo programa. Os municípios e estado (escolas municipais e estaduais) de Santa Catarina receberam, em 2015, R\$ 117,4 milhões do governo federal para a alimentação escolar (Fundo Nacional de Desenvolvimento da Educação, 2017).

A partir da lei n. 11.947 de 2009, desse total repassado pelo governo federal, $30 \%$ ( $\mathrm{R} \$ 33,9$ milhões) deveriam ser destinados para compras de produtos da agricultura familiar. Verifica-se, no entanto, que, em $2014 \mathrm{R} \$ 26,6$ milhões foram utilizados para compras diretas de agricultura familiar. Conforme se observa na Figura 1, a maioria dos produtos da agricultura familiar foi adquirida pela administração municipal, sendo que o estado de Santa Catarina teve apenas uma participação ínfima nas compras de alimentos provenientes do setor familiar para as escolas. A perspectiva para 2015 é de um avanço significativo nessas aquisições diretas, pois, de acordo com entrevistas ${ }^{6}$, a Secretaria do Estado de Santa Catarina adotou, ainda no início de 2015, um plano de ação que visa o cumprimento dos $30 \%$ de aquisições da

\footnotetext{
5 A projeção do IBGE para a população brasileira em 2014 é de 202 milhões. O Programa Nacional de Alimentação escolar atingiu, em 2014, 42,3 milhões de alunos (Fundo Nacional de Desenvolvimento da Educação, 2017).

6 A pesquisa de campo foi feita em 31 municípios e somaram 98 entrevistas que contemplaram agricultores familiares, responsáveis pela execução do PNAE e técnicos que apoiam a agricultura familiar.
}

agricultura familiar ainda nesse ano e destinação de 100\% dos recursos federais para a agricultura familiar até 2019 .

As compras de produtos da agricultura familiar pelo PNAE em Santa Catarina, e, portanto, a quantidade de alimentos da agricultura familiar destinada para alunos catarinenses, têm aumentado significativamente ano a ano. Esta mudança vem sendo considerada um avanço na qualidade da alimentação por pesquisadores da área de nutrição pela maior quantidade de alimentos frescos, diversificação dos produtos disponibilizados e adaptação às realidades regionais (Silva \& Sousa, 2013; Silverio \& Sousa, 2014). Do ponto de vista da geração de renda, houve ampliação do número de agricultores fornecedores que passaram a estar distribuídos por todos os municípios do estado. Esta distribuição é importante quando se percebe que, apesar de a realidade catarinense incluir uma parcela da agricultura familiar (15\% dos estabelecimentos) com renda superior a $\mathrm{R} \$ 169$ mil anuais, $17 \%$ dos agricultores são pouco integrados ao mercado e têm renda anual abaixo dos $R \$ 1.300$. A destinação dos recursos federais do PNAE para a agricultura familiar, se aplicada nas compras de produtos desta faixa de produtores de menor renda, poderia duplicar os ganhos de todos estes $17 \%$ de agricultores mais fragilizados.

\section{Metodologia}

Os resultados apresentados neste artigo têm origem em pesquisa com dados secundários, pesquisa de campo desenvolvida entre março e julho de 2015 e em análise 
Figura 2. Distribuição geográfica dos municípios selecionados para a pesquisa

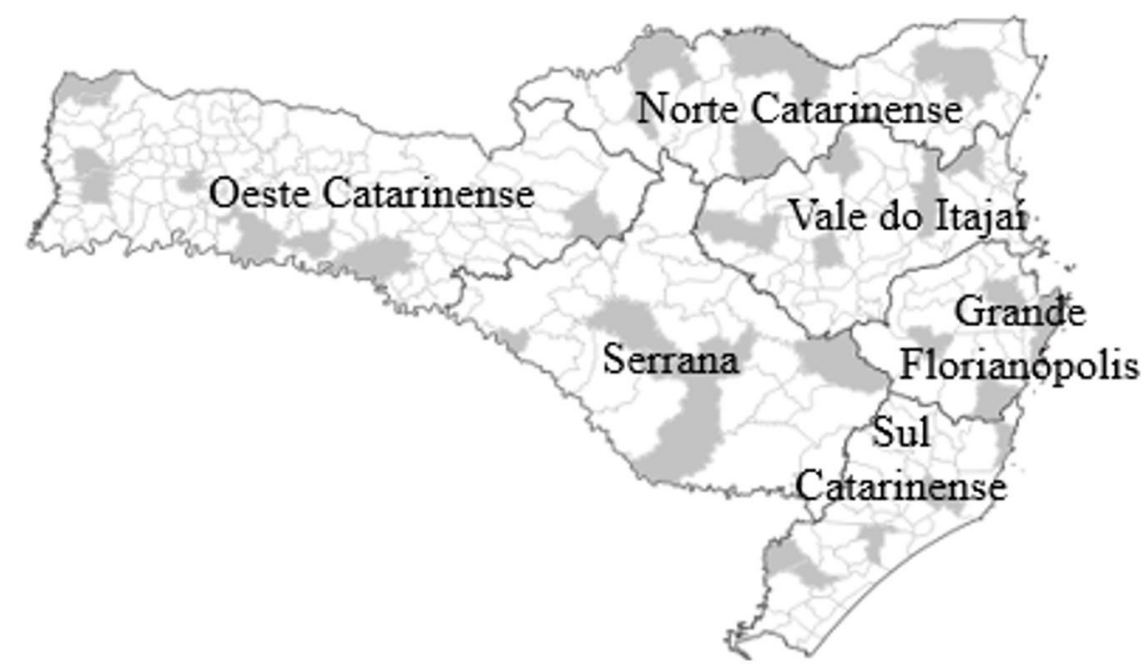

Fonte: Elaboração própria a partir de IBGE (Instituto Brasileiro de Geografia e Estatística, 2010).

de matriz insumo-produto. Os dados secundários contemplam levantamento bibliográfico, análise de informações da Produção Agrícola Municipal (PAM) e do Censo Agropecuário. A pesquisa de campo e a matriz insumo-produto são descritas nos próximos dois tópicos.

\subsection{Pesquisa de campo}

A pesquisa a campo contou com aplicação de três diferentes entrevistas semiestruturadas aplicadas com 98 atores. As entrevistas semiestruturadas foram construídas a partir de Fornazier (2014) e Mattei (2006) que abordaram a percepção dos atores frente ao PNAE.

A escolha dos municípios foi feita a partir de um plano de amostragem calculado via equação de determinação de tamanho da amostra aleatória (Bussab \& Morettin, 2004) - que considera a quantidade de recursos recebida pelo FNDE (Fundo Nacional de Desenvolvimento da Educação, 2017) - sendo selecionada uma amostra considerada representativa à realidade do estado de Santa Catarina, ou seja, 31 municípios. Os municípios foram distribuídos pelas mesorregiões catarinenses de maneira proporcional ${ }^{7}$ (Instituto Brasileiro de Geografia e Estatística, 2010) - quatro municípios no Norte, Serrana e Grande Florianópolis; cinco no Vale e no Sul e nove no Oeste - e estão marcados em cinza na Figura 2.

\footnotetext{
7 Na mesorregião Oeste foram selecionados nove municípios, nas mesorregiões Sul e Vale do Itajaí, cinco municípios em cada. Na Grande Florianópolis, Norte e Serrana, foram quatro em cada.
}

Os municípios foram selecionados de forma que, dentro de cada mesorregião, como demonstrado na Tabela 1, um terço fosse considerado desenvolvido (cinza escuro), um terço, médio desenvolvimento (cinza); e um terço, baixo desenvolvimento (cinza claro). O nível de desenvolvimento foi determinado pelo Índice de Desenvolvimento Humano Municipal (IDHM), IDHM Educação, taxa de atividade, renda per capita, população pobre e índice de Gini (Programa das Nações Unidas para o Desenvolvimento, 2015).

Nos municípios selecionados, os entrevistados foram contatados a partir de informações disponibilizadas pelas secretarias de educação e Epagri (Empresa de Pesquisa e Extensão Rural, administrada pelo governo do Estado). De maneira exploratória foi possível identificar atores relevantes na operacionalização da política e agricultores familiares envolvidos com o PNAE.

Foram aplicados três tipos de roteiro de perguntas semiestruturado. Um dos roteiros foi destinado aos agricultores e seus representantes e contou com questões sobre a forma de inserção nas vendas ao PNAE, a operacionalização do programa e os efeitos deste sobre as realidades individual e local. $\mathrm{O}$ segundo roteiro foi destinado para nutricionistas ou demais funcionários das secretarias de educação e entidades executoras da política; neste roteiro o enfoque foi dado às dificuldades na operacionalização e relação com agricultores. O terceiro roteiro foi destinado aos extensionistas da empresa de apoio ao agricultor familiar, que em Santa Catarina é representada pela Epagri (Empresa de Pesquisa e 
Tabela 1. Caracterização dos municípios alvo da pesquisa*

\begin{tabular}{|c|c|c|c|c|c|c|c|}
\hline Nome dos municípios & $\begin{array}{c}\text { IDHM } \\
(2010)\end{array}$ & $\begin{array}{l}\text { IDHM } \\
\text { Educação } \\
(2010)\end{array}$ & $\begin{array}{c}\text { Taxa de } \\
\text { atividade** } \\
-+18 \text { anos } \\
(2010)\end{array}$ & $\begin{array}{l}\text { Renda per } \\
\text { capita (2010) }\end{array}$ & $\begin{array}{c}\text { Pessoas } \\
\text { pobres (\%) } \\
(2010)\end{array}$ & $\begin{array}{l}\text { Índice de } \\
\text { Gini (2010) }\end{array}$ & $\begin{array}{c}\text { Recursos do } \\
\text { repassados } \\
\text { pelo FNDE } \\
(2017)\end{array}$ \\
\hline São José do Cerrito & 0,636 & 0,503 & 63,86 & 375 & 24,69 & 0,46 & 60.736 \\
\hline Santa Terezinha & 0,669 & 0,575 & 66,04 & 422 & 21,41 & 0,48 & 103.420 \\
\hline Bom Retiro & 0,699 & 0,559 & 76,27 & 639 & 9,68 & 0,46 & 87.080 \\
\hline Dionísio Cerqueira & 0,706 & 0,61 & 64,47 & 636 & 15,17 & 0,53 & 156.640 \\
\hline Doutor Pedrinho & 0,716 & 0,609 & 70,6 & 679 & 2,83 & 0,34 & 33.354 \\
\hline Paulo Lopes & 0,716 & 0,6 & 60,85 & 651 & 5,37 & 0,4 & 60.060 \\
\hline Celso Ramos & 0,719 & 0,692 & 64,97 & 459 & 12,06 & 0,39 & 42.220 \\
\hline Timbé do Sul & 0,72 & 0,606 & 71,44 & 710 & 4,21 & 0,47 & 46.208 \\
\hline Guarujá do Sul & 0,73 & 0,639 & 74,1 & 760 & 3,87 & 0,4 & 40.688 \\
\hline Fraiburgo & 0,731 & 0,637 & 67,95 & 674 & 9,14 & 0,48 & 565.832 \\
\hline Luiz Alves & 0,737 & 0,6 & 79,59 & 937 & 1,67 & 0,44 & 127.240 \\
\hline Biguaçu & 0,739 & 0,659 & 71,29 & 764 & 2,64 & 0,39 & 487.400 \\
\hline Turvo & 0,74 & 0,631 & 76,68 & 811 & 1,04 & 0,4 & 235.760 \\
\hline Descanso & 0,743 & 0,647 & 83,38 & 804 & 5,4 & 0,43 & 71.080 \\
\hline Rancho Queimado & 0,753 & 0,644 & 76,37 & 814 & 1,92 & 0,42 & 22.000 \\
\hline Canoinhas & 0,757 & 0,692 & 66,7 & 693 & 8,63 & 0,49 & 798.740 \\
\hline Taió & 0,761 & 0,67 & 79,63 & 848 & 1,81 & 0,43 & 232.240 \\
\hline Imbituba & 0,765 & 0,703 & 63,16 & 769 & 5,08 & 0,45 & 410.440 \\
\hline Lages & 0,77 & 0,697 & 66,89 & 878 & 6,24 & 0,54 & 1.917 .980 \\
\hline Mafra & 0,777 & 0,723 & 73,93 & 790 & 5,4 & 0,49 & 577.260 \\
\hline Seara & 0,779 & 0,674 & 82,56 & 1.188 & 1,47 & 0,51 & 129.428 \\
\hline Pinhalzinho & 0,783 & 0,716 & 81,11 & 894 & 2,23 & 0,43 & 182.380 \\
\hline Criciúma & 0,788 & 0,737 & 73,12 & 1.063 & 2,17 & 0,48 & 2.898 .888 \\
\hline Chapecó & 0,79 & 0,727 & 77,96 & 1.017 & 2,7 & 0,48 & 2.524 .428 \\
\hline Tubarão & 0,796 & 0,74 & 68,39 & 1.078 & 1,71 & 0,47 & 1.042 .000 \\
\hline Concórdia & 0,8 & 0,756 & 77,45 & 1.009 & 2,68 & 0,46 & 896.760 \\
\hline São Miguel do Oeste & 0,801 & 0,739 & 79,04 & 1.073 & 3,27 & 0,5 & 349.228 \\
\hline Rio do Sul & 0,802 & 0,727 & 75,46 & 1.114 & 2,03 & 0,45 & 979.960 \\
\hline Blumenau & 0,806 & 0,722 & 76,44 & 1.253 & 1,02 & 0,46 & 3.421 .110 \\
\hline Joinville & 0,809 & 0,749 & 74,21 & 1.127 & 1,67 & 0,49 & 5.468 .448 \\
\hline Florianópolis & 0,847 & 0,8 & 72 & 1.798 & 1,35 & 0,54 & 3.896 .736 \\
\hline
\end{tabular}

*Cinza claro: baixo desenvolvimento; cinza: desenvolvimento intermediário; cinza escuro: alto desenvolvimento. ${ }^{*}$ Percentual da população de 18 anos ou mais que era economicamente ativa em 2010.

Fonte: PNUD (Programa das Nações Unidas para o Desenvolvimento, 2015) e FNDE (Fundo Nacional de Desenvolvimento da Educação, 2017).

Extensão Rural), e abordou possíveis efeitos do PNAE no município, operacionalização do programa e interação com agricultores e secretarias da educação.

\subsection{Análise de Insumo-Produto}

A análise de Insumo-Produto permite a construção de uma 'fotografia econômica' da própria economia, que mostra como os setores estão relacionados entre si
(Guilhoto \& Sesso Filho, 2010). Portanto, essa técnica permite identificar interdependência entre setores ${ }^{8}$ (Guilhoto, 2011), como ilustrado na Figura 3. A partir

8 As transações e os fluxos de produtos de uma economia incluem os insumos e os produtos dos setores, importações e exportações, os impostos, a geração de emprego, o valor adicionado através de salários, remuneração de capital e terra agrícola. 
Figura 3. Cadeias produtivas que compõem as atividades econômicas

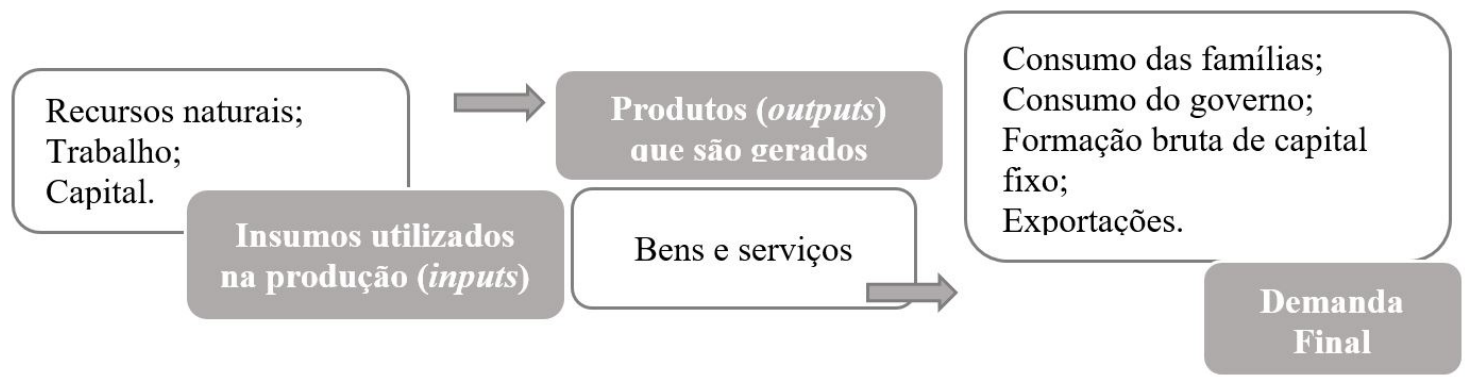

Fonte: Elaboração própria com base em Guilhoto (2011).

das inter-relações entre setores e economias é possível analisar os impactos de choques, ou seja, analisar como um recurso inserido na demanda final de um setor impacta nos setores de uma ou mais economias. A compilação das informações para a economia brasileira é feita em forma de Matriz Nacional de Insumo-Produto pelo Instituto Brasileiro de Geografia e Estatística (IBGE) desde a década de 1970. A Matriz Nacional é a base da matriz referente a regiões e setores feita anualmente, porém, divulgada com certa defasagem. A matriz utilizada aqui foi formulada a partir de Guilhoto (2011), com dados de 2009 disponibilizados pelo Núcleo de Economia Regional e Urbana da Universidade de São Paulo ${ }^{9}$ (Universidade de São Paulo \& Núcleo de Economia Regional e Urbana, 2019).

A partir da matriz de insumo-produto foi possível avaliar os impactos socioeconômicos das compras de produtos da agricultura familiar com recursos de alimentação escolar em Santa Catarina. A análise abrangeu a relação entre setores de Santa Catarina, dos efeitos diretos e indiretos do emprego dos recursos, bem como sua relação com os demais estados e regiões (Guilhoto et al., 2007; Miller \& Blair, 2009).

A complexidade das transações entre setores permite a identificação do quanto cada setor consome ou fornece em relação aos demais. Esta informação serve para identificar o que é produzido, quantos empregos são gerados, como são feitos os investimentos e quais insumos são necessários para suprir a demanda final de cada item produzido na economia. Os efeitos diretos e indiretos analisados separadamente permitem identificar

$9 \quad$ A matriz usada foi cedida pelo professor Joaquim José Martins Guilhoto, da Faculdade de Economia da USP - São Paulo, sendo fruto de sua pesquisa em conjunto com o professor Marcelo Pereira da Cunha, do Instituto de Economia da Unicamp. como são afetados os setores, no caso de compras diretas da agricultura, cuja ligação é imediata (direta) (insumos agrícolas), e de forma secundária (indireta) (siderurgia). A análise de estados e regiões permite identificar o nível de conexão entre as regiões, inclusive no que diz respeito à agricultura familiar, e a importância de cada transação e setor na economia, portanto, o quanto contribuem para o desenvolvimento econômico.

A Tabela 2 representa a Matriz de Insumo-Produto para uma economia de três setores. A análise da matriz foi feita a partir de choques, cujo significado é o de avaliar o impacto de inclusões de entradas na matriz e o seu resultado na recomposição e no valor adicional gerado em cada setor.

Na presente pesquisa, a matriz insumo-produto foi utilizada para a análise do impacto das compras diretas da agricultura a partir do PNAE. A análise do impacto foi feita a partir da comparação de dois cenários. O primeiro (A), de $100 \%$ de compras de produtos diretamente do comércio; o segundo (B), com destinação de $100 \%$ do recurso do FNDE para compras de agricultura.

O primeiro cenário (A), que representa compras do comércio, foi moldado a partir de um choque na matriz insumo-produto em que se mediu o impacto da destinação de $100 \%$ do recurso do Fundo Nacional de Desenvolvimento da Educação (FNDE) - recurso federal distribuído para estados e municípios com a finalidade de compra de alimentação escolar - em produtos do setor "comércio" (alimentos e bebidas).

O segundo cenário (B), que representa compras diretas da agricultura, foi calculado a partir de um choque na agricultura catarinense no âmbito do PNAE. A identificação da agricultura catarinense no âmbito do PNAE se deu dentro do setor "agricultura". Dentro do setor agricultura existem subitens que estão apresentados na Tabela 3. 
Tabela 2. Exemplo de uma Tabela de Insumo-Produto para uma economia de três setores

\begin{tabular}{|c|c|c|c|c|c|c|c|c|}
\hline & \multicolumn{3}{|c|}{ Setores } & \multirow{2}{*}{$\begin{array}{c}\text { Consumo } \\
\text { das } \\
\text { famílias }\end{array}$} & \multirow[b]{2}{*}{ Governo } & \multirow[b]{2}{*}{$I^{*}$} & \multirow[b]{2}{*}{$X^{* *}$} & \multirow[b]{2}{*}{ Total } \\
\hline & Agricultura & Pecuária & $\begin{array}{l}\text { Alimentos } \\
\text { e Bebidas }\end{array}$ & & & & & \\
\hline Agricultura & $Z_{11}$ & $Z_{12}$ & $Z_{13}$ & $\mathrm{C}_{1}$ & $\mathrm{G}_{1}$ & $\mathrm{I}_{1}$ & $\mathrm{E}_{1}$ & $X_{1}$ \\
\hline Pecuária & $Z_{21}$ & $Z_{22}$ & $Z_{23}$ & $\mathrm{C}_{2}$ & $\mathrm{G}_{2}$ & $\mathrm{I}_{2}$ & $\mathrm{E}_{2}$ & $X_{2}$ \\
\hline Alimentos e Bebidas & $Z_{31}$ & $\mathrm{Z}_{32}$ & $Z_{33}$ & $\mathrm{C}_{3}$ & $\mathrm{G}_{3}$ & $\mathrm{I}_{3}$ & $\mathrm{E}_{3}$ & $X_{3}$ \\
\hline Importação & $\mathrm{M}_{1}$ & $\mathrm{M}_{2}$ & $\mathrm{M}_{3}$ & $\mathrm{M}_{\mathrm{c}}$ & $\mathrm{M}_{\mathrm{g}}$ & $\mathrm{M}_{\mathrm{i}}$ & & M \\
\hline Impostos & $\mathrm{T}_{1}$ & $\mathrm{~T}_{2}$ & $\mathrm{~T}_{3}$ & $\mathrm{~T}_{\mathrm{c}}$ & $\mathrm{T}_{\mathrm{g}}$ & $\mathrm{T}_{\mathrm{i}}$ & $\mathrm{T}_{\mathrm{e}}$ & $\mathrm{T}$ \\
\hline Valor adicionado & $\mathrm{W}_{1}$ & $\mathrm{~W}_{2}$ & $\mathrm{~W}_{3}$ & & & & & $\mathrm{~W}$ \\
\hline Total & $X_{1}$ & $X_{2}$ & $X_{3}$ & $\mathrm{C}$ & G & I & E & \\
\hline
\end{tabular}

*Investimento. ${ }^{* *}$ Exportação.

Fonte: Guilhoto (2011).

Tabela 3. Compras por item em relação ao total e valor em Reais relativo ao cenário em que $100 \%$ do recurso do FNDE é destinado para a agricultura familiar

\begin{tabular}{lcc}
\hline \multicolumn{1}{c}{ Produto $^{*}$} & Proporção (\%) & Valor em reais \\
\hline Outros produtos e serviços da lavoura & 31,20 & 35.226 .882 \\
Outros produtos alimentares & 18,30 & 20.622 .892 \\
Fruticultura & 17,90 & 14.071 .075 \\
Bovinos, aves e suínos & 11,40 & 5.535 .555 \\
Leite, produtos do laticínio e sorvetes & 7,60 & 5.260 .627 \\
Mandioca & 4,00 & 4.516 .666 \\
Feijão & 2,40 & 2.705 .680 \\
Bebidas & 2,30 & 2.560 .498 \\
Outros produtos & 5,10 & 5.690 .792 \\
Total & 100 & $\mathrm{R} \$ 112,9$ milhões
\end{tabular}

${ }^{*}$ Os produtos dispostos nesta tabela são subitens do setor agricultura da matriz insumo-produto disponibilizada pelo Nereus-USP (Universidade de São Paulo \& Núcleo de Economia Regional e Urbana, 2019).

Fonte: Dados de 821 escolas estaduais de autogestão fornecidos pelo SED-SC (Santa Catarina, 2013) e FNDE (Fundo Nacional de Desenvolvimento da Educação, 2017).

A distribuição do valor total do choque entre os subitens do setor agricultura foi atribuída a partir da proporção de compras de cada item alimentar proveniente da agricultura familiar adquirido por 821 escolas catarinenses. As compras efetuadas pelas escolas representam $61 \%$ das escolas estaduais e estão distribuídas pelas seis mesorregiões catarinenses os dados são de 2012 (Santa Catarina, 2013) e são as únicas informações disponíveis com detalhamento por item adquirido. $\mathrm{O}$ valor dos choques equivale ao total de recurso federal enviado para o estado e municípios de Santa Catarina em 2014 (R\$ 112,9 milhões) (Fundo Nacional de Desenvolvimento da Educação, 2017).

O estado de Santa Catarina dispõe, segundo o censo de 2006, de $92 \%$ dos estabelecimentos agrícolas familiares, assim como $58 \%$ da área e $68 \%$ da renda. São alguns exemplos: a produção vegetal (horticultura) possui $83 \%$ da produção familiar; produção vegetal (lavouras temporárias), 76\%; agroindústria, 73\%, e leite de vaca, 90\% (Instituto Brasileiro de Geografia e Estatística, 2006)

Os produtos citados representam a maior parte dos itens observados na Tabela 3; portanto, tais ponderações e a presença majoritária da agricultura familiar na agricultura catarinense fez com que se considerasse assumir para o âmbito deste trabalho as compras diretas da agricultura catarinense como majoritariamente familiares e, portanto, passível das análises de impacto desenvolvidas.

\section{Efeitos do PNAE sobre a Agricultura Familiar}

A partir dos resultados extraídos de 98 entrevistas semiestruturadas aplicadas junto aos agricultores, técnicos de apoio à agricultura familiar e responsáveis 
pela execução do PNAE em 31 municípios catarinenses, foi possível analisar a operacionalização do PNAE e suas consequências para as realidades locais. A pesquisa não excluiu municípios que não adquirem produtos da agricultura familiar; portanto, parte da análise considera também as razões do não cumprimento da lei. Nos itens seguintes se busca discutir os temas centrais encontrados nas entrevistas e informações retiradas do banco de dados do FNDE, corroborando resultados da pesquisa.

A presença da agricultura familiar e suas organizações determinaram onde a política seria mais rapidamente implementada e com que nível de qualidade. Porém, independente das condições de cada mesorregião catarinense, todas ampliaram as compras de produtos da agricultura familiar para a alimentação escolar ao longo do tempo, como mostram também os dados do FNDE na Tabela 4. Quanto à razão da ampliação das compras em municípios e mesorregiões, desde o início da vigência da política a resposta mais frequente encontrada entre as entrevistas está no arranjo institucional.

Na mesorregião Serrana, as razões do baixo desempenho em comparação com as demais mesorregiões (Tabela 4) são atribuídas à presença de propriedades de maior extensão e menor quantidade de agricultores familiares. Porém, é possível observar que a renda garantida impactou na estruturação dos agricultores, visto que em 57\% dos municípios visitados foi mencionada a aplicação da renda proveniente do PNAE em melhorias na propriedade. No município de Celso Ramos, por exemplo, a renda do PNAE tem sido um incentivo importante para a construção de estrutura para seleção e embalagem da laranja, que é distribuída em municípios como Lages, o maior da mesorregião. Em Timbé do Sul (Sul), São Miguel do Oeste (Oeste) e Lages (Serrana) verificou-se, tanto por parte dos agricultores como por parte das instituições de educação e assistência técnica, que houve incentivo para que os agricultores envolvidos voltassem ou passassem a produzir maior diversidade de produtos alimentares.

O Vale do Itajaí e o Norte Catarinense têm características semelhantes, principalmente no que se refere à menor articulação entre agricultores, que mostra ser a justificativa para o desempenho médio das mesorregiões (Tabela 4). Diante da desarticulação, a cooperação entre instituições públicas e organizações de agricultores foi determinante para impulsionar a criação de cooperativas, pequenas agroindústrias e, assim, incentivar o envolvimento dos agricultores com compras institucionais.

Na Grande Florianópolis, mesmo com menor presença de agricultores, tem ocorrido um aumento da produção, inclusive orgânica, nos municípios agrícolas próximos. O restante da demanda tem sido suprido a partir da articulação com cooperativas de outras regiões.

O Oeste e o Sul têm vantagens já estabelecidas: grande presença de agricultura familiar e suas organizações detêm o melhor desempenho do estado em relação às compras de produtos da agricultura familiar pelo PNAE e se utilizam destas compras para aumentar o suporte para as estruturas existentes e o incentivo para ampliação e fortalecimento de suas atividades. No Sul Catarinense foram identificadas 13 novas cooperativas que tiveram no PNAE uma das razões de sua fundação (Estevan \& Mior, 2014). Uma das cooperativas entrevistadas mencionou que a razão do bom desempenho do Sul em relação ao PNAE se deve ao fato de que os agricultores já estavam organizados devido às entregas anteriores que eram realizadas para o PAA.

A formação de um arranjo entre instituições públicas (secretarias de educação, empresas de apoio aos agricultores familiares, prefeituras e demais estruturas) e privadas (especialmente cooperativas de agricultores familiares) se mostra determinante na ampliação do PNAE. Se, por um lado, os municípios cuja aplicação do recurso para

Tabela 4. Proporção de municípios que destinaram 30\% ou mais do recurso da alimentação escolar para a compra de produtos da agricultura familiar - Santa Catarina e mesorregiões (\%)

\begin{tabular}{lcccc}
\hline & $\mathbf{2 0 1 1}$ & $\mathbf{2 0 1 2}$ & $\mathbf{2 0 1 3}$ & $\mathbf{2 0 1 4}$ \\
\hline Municípios de Santa Catarina & 79 & 85 & 86 & 88 \\
Serrana & 67 & 80 & 57 & 67 \\
Oeste Catarinense & 81 & 84 & 92 & 92 \\
Vale do Itajaí & 85 & 93 & 91 & 93 \\
Grande Florianópolis & 67 & 67 & 76 & 76 \\
Norte Catarinense & 96 & 96 & 81 & 92 \\
Sul Catarinense & 72 & 83 & 89 & 91 \\
\hline
\end{tabular}

Fonte: FNDE (Fundo Nacional de Desenvolvimento da Educação, 2017). 
a aquisição de produtos da agricultura familiar pode ser considerada um sucesso (compram além dos 30\%), e possuem perspectiva de avanço, contam com um arranjo institucional ou com uma equipe consolidada na entidade executora com o intuito de buscar meios para transpor barreiras. Por outro, municípios que demoraram a buscar o cumprimento da legislação e adquirem produtos da agricultura familiar há menos de dois anos têm muita dificuldade em cumprir a lei. As compras de produtos da agricultura familiar exigem uma estrutura de ação por parte da entidade executora para entrar em contato com os agricultores; fomentar a produção dos itens desejados e garantir quantidade, preço e período em que serão efetivadas as compras.

\subsection{Renda e transformação produtiva e organizacional}

Um dos temas mais destacados nas entrevistas com agricultores, representantes da instituição compradora e de assistência técnica foi a unânime opinião de que houve impacto das aquisições do PNAE na renda do agricultor. A 'renda garantida' e a 'compra garantida' foram mencionadas como as principais vantagens do programa, que impactam diretamente na renda dos agricultores. Alguns entrevistados fizeram a conexão entre PNAE e desenvolvimento local - a renda vinda do PNAE como um recurso novo que, ao chegar no município e ser posto nas mãos do agricultor, gera movimentação do comércio local, devido à demanda por bens de consumo e investimentos na propriedade. Houve, também, atribuição ao PNAE pela melhoria na estrutura produtiva e organizacional das propriedades - o que os permitiu acessar outros mercados. Parte dos agricultores mencionou também o PAA como política que gerou resultados semelhantes.

Quanto à produção, em mais de $80 \%$ dos municípios visitados foi declarado aumento da diversificação produtiva a partir das compras do PNAE - incluindo produtos agroindustriais. Houve menção também à pluriatividade e criação de agroindústria devido à possibilidade de vendas de produtos com maior valor agregado como sucos, pães, bolachas e doces. Houve estímulo ao cultivo de produtos indisponíveis e aumento da produção de outros que anteriormente eram pouco valorizados, caso de hortifrutigranjeiros.

No que se refere à diversificação da produção em municípios com compras de agricultura familiar, estes se dividem em três grupos dispostos no Quadro 1 .
No primeiro, contam com agricultores que se especializam em uma ou duas atividades e perderam o hábito de produção de alimentos para subsistência. Nestes municípios, compras de produtos pelo PNAE, como hortifrutícolas, eram feitas em mercados distantes, por vezes através de empresas de comercialização de alimentos, e passaram a ser feitas localmente a partir do arranjo entre prefeitura, Empresa de Pesquisa e Extensão Rural do estado (Epagri) e agricultores, o que gerou a disponibilidade de maior variedade e qualidade de produtos frescos da agricultura familiar. O segundo grupo de municípios não apresenta aumento da diversificação da produção da agricultura familiar, alguns não possuem agricultura familiar, as compras do PNAE não ocorreram ou foram pequenas. $O$ terceiro grupo também não apresentou aumento da diversificação e é composto por municípios com agricultura familiar previamente bastante organizada, caso de Seara, cujos agricultores dispõem de duas grandes casas coloniais para atenderem a população local com hortifruticultura, massas, pães e demais produtos da agropecuária e agroindústria familiar.

Entre os fatores que detêm o processo de ampliação do número de agricultores familiares fornecedores no PNAE, foi citada a resistência do agricultor em investir em algo que lhe pareça novo ou fazer uma nova tentativa diante de experiências anteriores malsucedidas. A resistência se aplica na agroindustrialização, no associativismo e no cooperativismo. Esta é a realidade do Norte Catarinense, carente de formas associativas e de processamento de produtos, e diferente do Oeste Catarinense, cujas atividades da agricultura familiar são as mais desenvolvidas do estado. Esta resistência, para ser rompida, requer um conjunto de incentivos que diminua a percepção de risco do agricultor. Diante disso, as compras institucionais foram consideradas um incentivo palpável para transpor estas limitações.

\subsection{Logística}

A partir das entrevistas, se observa que a garantia de demanda e preço, a disponibilidade de apoio técnico, estruturas logísticas e produtivas públicas junto à atuação dos agricultores de forma cooperativa - acúmulo de esforços gerenciais e de capitais - geram inserção produtiva e transformação das economias locais. Estes são fatores tidos como determinantes para que os problemas produtivos e logísticos (escala e transporte) sejam solucionados. 
Quadro 1. Diversificação da produção entre os municípios visitados durante a pesquisa a partir da implementação do PNAE

\begin{tabular}{|c|c|c|}
\hline $\begin{array}{l}\text { Há maior diversificação na produção - } \\
\text { Agricultores sem hábito de produção } \\
\text { para subsistência que ampliaram a } \\
\text { diversificação produtiva }\end{array}$ & $\begin{array}{l}\text { Não há maior diversificação na } \\
\text { produção - agricultura familiar não } \\
\text { existe ou tem presença irrisória }\end{array}$ & $\begin{array}{c}\text { Não há maior diversificação na } \\
\text { produção - possuem agricultura } \\
\text { familiar consolidada }\end{array}$ \\
\hline São José do Cerrito & Biguaçu & Celso Ramos \\
\hline Lages & Florianópolis & Chapecó \\
\hline Bom Retiro & Imbituba & Seara \\
\hline Concórdia & Paulo Lopes & Turvo \\
\hline Descanso & Rancho Queimado & Criciúma \\
\hline Dionísio Cerqueira & Luiz Alves & Rio do Sul \\
\hline \multicolumn{3}{|l|}{ Guarujá do Sul } \\
\hline \multicolumn{3}{|l|}{ Pinhalzinho } \\
\hline \multicolumn{3}{|l|}{ São Miguel do Oeste } \\
\hline \multicolumn{3}{|l|}{ Fraiburgo } \\
\hline \multicolumn{3}{|l|}{ Timbé do Sul } \\
\hline \multicolumn{3}{|l|}{ Tubarão } \\
\hline \multicolumn{3}{|l|}{ Joinville } \\
\hline \multicolumn{3}{|l|}{ Santa Terezinha } \\
\hline \multicolumn{3}{|l|}{ Canoinhas } \\
\hline \multicolumn{3}{|l|}{ Mafra } \\
\hline \multicolumn{3}{|l|}{ Taió } \\
\hline \multicolumn{3}{|l|}{ Doutor Pedrinho } \\
\hline Blumenau & & \\
\hline
\end{tabular}

Fonte: Elaboração própria, a partir dos resultados da pesquisa.

A logística, apesar de ser um ponto sensível na operacionalização do programa, deixa de ser um empecilho nos municípios que contabilizam mais de quatro anos atuando com o PAA e/ ou o PNAE. Problemas considerados indissolúveis no início das compras institucionais foram superados a partir da organização dos agricultores (pagamento de funcionário para fazer entregas ou divisão de tarefas entre cooperados no caso de cooperativas) e apoio das entidades executoras (disponibilidade de locais para centralizar as entregas dos agricultores familiares e distribuição ponto-a-ponto nas escolas a cargo da prefeitura).

Santa Catarina tem, como exemplo da factibilidade da organização entre agricultores, cooperativas que possuem condição organizacional para atender os grandes municípios e o estado de Santa Catarina, inclusive em entregas ponto-a-ponto (em cada escola atendida). Entre as organizações que se destacam na sua capacidade de organização da produção e das entregas estão as três cooperativas centrais, Ucaf (Unidade Central das Agroindústrias Familiares), que atua junto da Apaco
(Associação dos Pequenos Agricultores do Oeste Catarinense), com sede em Chapecó; Cecaf (Central das Cooperativas da Agricultura Familiar) em Concórdia; e CCA (Cooperativa Central de Reforma Agrária de Santa Catarina), com sede em São Miguel do Oeste. A Apaco e a Cecaf foram visitadas durante a pesquisa e atestaram abranger mais de 100 cooperativas cada, superando 10 mil agricultores associados cada uma.

Em situações em que os agricultores não se dispunham de forma previamente organizada, a solução encontrada por prefeituras para cooperativas menores e agricultores individuais foi disponibilizar uma central de recebimento de mercadorias ${ }^{10}$ e se responsabilizar pelas entregas

10 A construção de uma estruturação de recepção dos produtos é proveniente de repasses que, muitas vezes, vêm de projetos do Ministério do Desenvolvimento Agrário (MDA). De acordo com dados repassados em entrevistas, este tipo de estruturação, com foco no PNAE, está em processo de ser implementado em mais 12 municípios catarinenses dada a disponibilidade de $\mathrm{R} \$ 3$ milhões do MDA para a Secretaria de Combate à Fome do Estado e articulação com o Conselho Nacional de Segurança Alimentar e Nutricional (Consea). 
Tabela 5. Responsabilidade das entregas nas unidades educacionais municipais - SC

\begin{tabular}{lcccc}
\hline $\begin{array}{c}\text { Municípios por quantidade } \\
\text { de recurso recebidos pelo } \\
\text { FNDE }\end{array}$ & $\begin{array}{c}\text { Prefeitura efetua entregas* } \\
\mathbf{( \% )}\end{array}$ & $\begin{array}{c}\text { Entregas de } \\
\text { responsabilidade } \\
\text { compartilhada (\%) }\end{array}$ & $\begin{array}{c}\text { Entregas são de } \\
\text { responsabilidade dos } \\
\text { agricultores (\%) }\end{array}$ \\
\hline Acima de 350 mil & 11 & 33 & 56 & 100 \\
De 60 mil a menos de 350 mil & 17 & 33 & 50 & 100 \\
Até 60 mil & 22 & 11 & 67 & 57 \\
Total & 17 & 27 & 100 \\
\hline
\end{tabular}

*6\% do total dos municípios têm cozinha central, ou seja, entrega e preparo centralizados e distribuição da alimentação pronta para as escolas.

Fonte: Elaboração própria, a partir dos resultados da pesquisa.

ponto-a-ponto, permitindo que os agricultores entreguem todos os produtos em um só lugar. Os custos para a prefeitura não aumentam, visto que parte do valor que seria repassado ao agricultor para efetuar a logística é utilizado pela prefeitura.

As soluções para operacionalização das entregas dependem da características de cada município, que inclui disponibilidade de recursos para criar uma estrutura de recepção de produtos, ou mesmo manipulação, e nível organizacional dos agricultores. Como é possível observar na Tabela 5, não há uma relação da quantidade de recursos que o município recebe que está ligada ao tamanho do município e à forma em que as entregas são efetuadas.

A logística é apontada como ponto capaz de limitar ou impossibilitar as compras de agricultura familiar apenas em municípios que: não contam com diálogo entre agricultores e suas entidades representativas e a prefeitura e possuem baixa intensidade de atuação de assistência técnica e extensão rural junto aos agricultores fornecedores. A relação entre estes dois fatores foi obtida a partir de interpretação das respostas dadas nas entrevistas. Destes municípios, apenas um não comprava da agricultura familiar, mas já havia se organizado para passar a comprar em 2015.

\section{Análise da matriz IxP: o PNAE e Agricultura familiar}

Neste item será analisado o significado das compras de produtos diretamente da agricultura em impacto socioeconômico como forma de compreender o efeito dinamizador de formas direta e indireta.

A metodologia de insumo-produto permite avaliar impactos de novas formas de emprego de recursos nas economias através dos fluxos anuais monetários e bens e serviços entre diferentes setores da economia e de diferentes regiões, dispostos na matriz de insumo-produto (IxP). A forma de análise utilizada neste estudo aborda a agricultura familiar como um setor e utiliza a matriz IxP para estudos sobre sua inter-relação para com os demais setores do estado Santa Catarina de forma similar ao que foi feito por Guilhoto et al. (2007).

Ao construir uma matriz com as inter-relações entre setores de Santa Catarina, é possível verificar como um recurso inserido em determinado setor se distribui pela economia catarinense, gerando efeitos diretos e indiretos. A inserção de um recurso em determinado setor é denominada "choque". Neste artigo, foram feitos dois diferentes "choques" que são representados por dois cenários: o primeiro (A) trata de compras de alimentação no comércio e o segundo (B), de compras diretas da agricultura.

No que se refere aos valores utilizados para compra de alimentação escolar, têm duas fontes: parte do recurso é do governo federal e parte, dos municípios e estados ${ }^{11}$. Os recursos são repassados para as entidades executoras do PNAE, secretarias da educação dos municípios (escolas municipais que atendem, de modo geral, creches e, por vezes, ensino fundamental) e estados (escolas estaduais que, em geral, atendem alunos dos ensinos fundamental e médio). O recurso federal repassado para Santa Catarina em 2014 foi de R\$ 112,9 milhões.

As compras diretas via PNAE da agricultura são destinadas à agricultura familiar. A análise de cenários conta com o cenário B, que contempla impactos diretos sobre a agricultura catarinense. Argumentos que constam na metodologia justificam as razões para considerar que os impactos sobre a agricultura catarinense representam

\footnotetext{
11 O estado e os municípios contribuem, em média, com valor semelhante ao recurso federal.
} 
impactos sobre a agricultura familiar catarinense, visto que a agricultura de SC é majoritariamente familiar e que os itens desagregados da matriz insumo-produto possuem presença ainda mais ampla da agricultura familiar em sua produção.

\subsection{Cenários}

O primeiro cenário $(\mathrm{A})$ reflete a realidade observada no período anterior a 2009, quando não havia obrigatoriedade nas compras de agricultura familiar e o modelo de compras, via licitação, gerava impedimentos para o acesso de agricultores familiares. As compras eram feitas majoritariamente via comércio. O segundo cenário $(B)$ reflete a realidade factível de ser atingida nos próximos anos de destinação de $100 \%$ dos recursos provenientes do FNDE para as compras diretas da agricultura. Os municípios e o estado vêm ampliando as aquisições diretas da agricultura familiar e é possível antever que este patamar possa ser atingido na próxima década, caso a política seja fomentada pelos governos. Ambos os choques (cenários A e B) são no valor de R\$112,9 milhões, $100 \%$ dos recursos recebidos por Santa Catarina em 2014.

No Cenário A, de compras via comércio, a maioria dos recursos é absorvida pelo comércio: 53\% (R\$ 60 milhões), 23\% (R\$ 26 milhões) do recurso é destinado ao setor de agricultura, 4\% (R\$ 5 milhões), ao de pecuária e 19\% (R\$ 22 milhões), ao de alimentos e bebidas. Neste cenário, o multiplicador de produção é 1,59. O multiplicador significa que, para cada $\mathrm{R} \$ 1,00$ destinado às compras para alimentação escolar, pelo FNDE, o valor da produção de todos os setores da economia necessário para atender esta demanda (de R\$ 1,00) é de R\$ 1,59. Este valor da produção contempla os efeitos diretos e indiretos da cadeia produtiva para atender à demanda de $\mathrm{R} \$ 1,00$. A distribuição dos recursos consta na Tabela 6.

No Cenário B, todo o recurso é direcionado para a agricultura familiar, sendo 56\% (R\$ 63 milhões) do recurso destinado ao setor de agricultura, 7\% (R\$ 8 milhões), ao de pecuária e 36\% (R\$ 41 milhões), ao de alimentos e bebidas. A razão entre o choque na economia de R \$112,9 milhões e o valor de produção gerado (impacto total na produção dos setores da economia) corresponde ao número 1,79, que é o multiplicador que consta também na Tabela 6. Portanto, cada Real destinado às compras no Cenário B gera impacto total à economia de $\mathrm{R} \$ 1,79$.

O Cenário A gera R\$ 179,3 milhões de valor da produção (Tabela 6). A soma de R\$179,3 milhões representa o total gerado, efeitos diretos e indiretos, a partir dos R\$112,9 milhões inseridos na economia via choque. Estes R \$179,3 milhões são distribuídos de forma que os setores mais atingidos de Santa Catarina são: comércio e serviços (42,3\%), agricultura e pecuária $(20,7 \%)$ e alimentos e bebidas $(12,8 \%)$, como consta na Tabela 7 . No Cenário B, do total do Produto Interno Bruto (PIB) para remuneração do

Tabela 6. Distribuição dos recursos na matriz insumo-produto e o multiplicador da produção

\begin{tabular}{|c|c|c|c|}
\hline \multicolumn{4}{|c|}{ Cenário A } \\
\hline Setor & Choque & Setor & Impacto \\
\hline Agricultura SC & R\$ 26 milhões & Produção total & D\& $170 \Omega$ 2 \\
\hline Pecuária SC & R\$ 5 milhões & Brasil & K\$ 1/9,3 milhoes \\
\hline Alimentos e bebidas SC & R\$ 22 milhões & & \\
\hline Comércio & R\$ 60 milhões & & \\
\hline Total & R\$ 112,9 milhões & MP-I & 1,59 \\
\hline \multicolumn{4}{|c|}{ Cenário B } \\
\hline Setor & Choque & Setor & Impacto \\
\hline Agricultura SC & R\$ 63 milhões & Produção total & $\mathrm{R} \$ 202,6$ \\
\hline Pecuária SC & R\$ 8 milhões & Brasil & milhões \\
\hline Alimentos e bebidas SC & R\$ 41 milhões & & \\
\hline Comércio & 0 & & \\
\hline Total & R\$ 112,9 milhões & MP-I & 1,79 \\
\hline
\end{tabular}

Fonte: Elaboração própria com base nos resultados do modelo de insumo-produto empregado na pesquisa. 
Tabela 7. Impactos totais do emprego do recurso de acordo com os cenários a partir da matriz insumo-produto sobre os setores (milhões de Reais de 2014) e o emprego (em unidades)

\begin{tabular}{|c|c|c|c|c|c|c|}
\hline & \multicolumn{3}{|c|}{ Cenário A } & \multicolumn{3}{|c|}{ Cenário B } \\
\hline & $\begin{array}{c}\text { Santa } \\
\text { Catarina }\end{array}$ & $\begin{array}{l}\text { Demais } \\
\text { estados }\end{array}$ & Brasil & $\begin{array}{c}\text { Santa } \\
\text { Catarina }\end{array}$ & $\begin{array}{l}\text { Demais } \\
\text { estados }\end{array}$ & Brasil \\
\hline Produção -Agricultura & 27,045 & 4,31 & 31,355 & 63,595 & 8,101 & 71,696 \\
\hline Produção-Pecuária & 10,033 & 2,435 & 12,467 & 18,794 & 4,395 & 23,189 \\
\hline Produção -Alimentos e bebidas & 22,999 & 5,22 & 28,22 & 43,187 & 9,745 & 52,932 \\
\hline Produção-Indústria da transformação & 4,591 & 15,63 & 20,22 & 4,589 & 23,441 & 28,031 \\
\hline Produção -Construção civil & 0,133 & 0,135 & 0,268 & 0,065 & 0,133 & 0,198 \\
\hline Produção -Comércio e serviços & 75,878 & 10,924 & 86,801 & 13,855 & 12,678 & 26,532 \\
\hline Importação & 6,172 & 2,121 & 8,293 & 8,05 & 3,374 & 11,425 \\
\hline Impostos & 5,654 & 1,919 & 7,574 & 6,236 & 2,887 & 9,124 \\
\hline Remuneração trabalho & 55,261 & 8,912 & 64,172 & 58,182 & 13,252 & 71,434 \\
\hline Remuneração capital & 26,505 & 6,355 & 32,86 & 12,222 & 8,694 & 20,917 \\
\hline Empregos & 3.615 & 726 & 4.341 & 4.160 & 1.231 & 5.390 \\
\hline PIB & 87,4 & 17,2 & 104,6 & 76,6 & 7,1 & 101,5 \\
\hline
\end{tabular}

Fonte: Elaboração própria com base nos resultados do modelo de insumo-produto empregado na pesquisa.

trabalho e do capital e impostos, $83,3 \%$ permanecem em Santa Catarina e o restante vai para os demais estados.

$\mathrm{Na}$ economia catarinense, a principal diferença entre os cenários é o menor impacto causado em sua agricultura e recurso total. A economia catarinense recebe R\$ 8,7 milhões a menos no Cenário B em relação ao A. Porém, o valor da produção do Cenário B é R\$3,4 milhões maior em relação ao A, em 20,5\% quanto aos impostos, $37,8 \%$, às importações e $11,3 \%$, à remuneração trabalho. $\mathrm{O}$ único item que diminuiu em participação foi o de remuneração de capital.

Do total do Produto Interno Bruto (PIB), recorte da economia que inclui remuneração do trabalho e do capital e impostos, o PIB do Cenário A é 3\% maior que o do B. A principal região com maior diferença é Santa Catarina, cujo PIB gerado no A é $12,3 \%$ maior que no B e a remuneração de capital, 53,9\% maior, em benefício do aumento dos impactos nas demais regiões e da elevação na somatória do País dos impostos, importações, remuneração de trabalho e empregos. O Cenário $\mathrm{B}$ possui, em relação ao valor da produção, 20,5\% maior arrecadação de impostos que o Cenário A, 37,8\% em importação e 11,3\% em remuneração trabalho. O único item que tem valor menor no B é a remuneração de capital. Em relação aos impactos gerados no valor da produção em toda a economia, R \$202,6 milhões, o total é superior ao gerado no Cenário A, de R\$179,3 milhões.
A remuneração do trabalho no Cenário A (Tabela 7) gera impacto de $\mathrm{R} \$ 55,3$ milhões, $\mathrm{R} \$ 26,5$ milhões para remuneração do capital e de $\mathrm{R} \$ 11,8$ milhões para importação e impostos. Portanto, 48,9\% do impacto desta demanda é para a remuneração do trabalho. A remuneração do trabalho, $\mathrm{R}$ \$ 55,3 milhões, se divide de forma que $86,1 \%$ ficam no estado de Santa Catarina. Os empregos gerados na economia catarinense são 3.615, 83,3\% dos 4.341 empregos criados em todo o Brasil.

A remuneração do trabalho no cenário $B$, no entanto, gera soma de R\$ 71,4 milhões, R \$20,9 milhões para remuneração do capital e R\$10,3 milhões para importação e impostos. Portanto, 63,3\% do total da destinação do recurso é para a remuneração do trabalho, superando em $6,4 \%$ o Cenário A. Dentre o recurso destinado para remuneração do trabalho, os $\mathrm{R} \$ 71,4$ milhões, R\$ 58,2 milhões (ou 81,4\%) ficam no estado de Santa Catarina. Os empregos gerados na economia catarinense somaram 4.160 do total de 5.390 empregos criados em todo o Brasil. Esse número é 15,1\% superior ao Cenário A, no que se refere à Santa Catarina, e $24,2 \%$ superior no que se refere ao Brasil. A maioria do valor da produção em SC foi destinada para comércio e serviços, o que não ocorre nas demais regiões, cuja maior parte do impacto foi absorvido pela indústria de transformação. Em relação à análise de efeitos diretos e indiretos da Tabela 8, Santa Catarina, por receber 
Tabela 8. Efeitos totais dos cenários (milhões de reais de 2014)

\begin{tabular}{|c|c|c|c|c|c|c|}
\hline \multirow[b]{2}{*}{ Efeito total } & \multicolumn{3}{|c|}{ Cenário A } & \multicolumn{3}{|c|}{ Cenário B } \\
\hline & $\begin{array}{c}\text { Santa } \\
\text { Catarina }\end{array}$ & $\begin{array}{l}\text { Demais } \\
\text { estados }\end{array}$ & Brasil & $\begin{array}{c}\text { Santa } \\
\text { Catarina }\end{array}$ & $\begin{array}{l}\text { Demais } \\
\text { estados }\end{array}$ & Brasil \\
\hline Produção - Agricultura & 27,05 & 4,31 & 31,36 & 63,60 & 8,10 & 71,70 \\
\hline Produção - Pecuária & 10,03 & 2,43 & 12,47 & 18,79 & 4,40 & 23,19 \\
\hline Produção - Alimentos e bebidas & 23,00 & 5,22 & 28,22 & 43,19 & 9,75 & 52,93 \\
\hline Produção - Indústria transformação & 4,59 & 15,63 & 20,22 & 4,59 & 23,44 & 28,03 \\
\hline Produção - Construção civil & 0,13 & 0,14 & 0,27 & 0,07 & 0,13 & 0,20 \\
\hline Produção - Comércio e serviços & 75,88 & 10,92 & 86,80 & 13,86 & 12,68 & 26,53 \\
\hline Total & 140,68 & 38,65 & 179,33 & 144,09 & 58,49 & 202,58 \\
\hline
\end{tabular}

Fonte: Elaboração própria com base nos resultados do modelo de insumo-produto empregado na pesquisa.

Tabela 9. Efeitos indiretos dos cenários (milhões de Reais de 2014)

\begin{tabular}{|c|c|c|c|c|c|c|}
\hline \multirow[b]{2}{*}{ Efeito indireto } & \multicolumn{3}{|c|}{ Cenário A } & \multicolumn{3}{|c|}{ Cenário B } \\
\hline & $\begin{array}{c}\text { Santa } \\
\text { Catarina }\end{array}$ & $\begin{array}{l}\text { Demais } \\
\text { estados }\end{array}$ & Brasil & $\begin{array}{c}\text { Santa } \\
\text { Catarina }\end{array}$ & $\begin{array}{l}\text { Demais } \\
\text { estados }\end{array}$ & Brasil \\
\hline Produção - Agricultura & 0,371 & 2,542 & 2,913 & 0,652 & 4,446 & 5,098 \\
\hline Produção - Pecuária & 0,309 & 0,9 & 1,209 & 0,562 & 1,647 & 2,209 \\
\hline Produção - Alimentos e bebidas & 0,654 & 2,193 & 2,847 & 1,166 & 3,95 & 5,116 \\
\hline Produção - Indústria transformação & 1,472 & 10,068 & 11,54 & 1,511 & 14,714 & 16,225 \\
\hline Produção - Construção civil & 0,066 & 0,116 & 0,182 & 0,04 & 0,127 & 0,167 \\
\hline Produção - Comércio e serviços & 3,58 & 7,472 & 11,052 & 3,747 & 10,5 & 14,247 \\
\hline Total & 6,452 & 23,291 & 29,743 & 7,678 & 35,385 & 43,063 \\
\hline
\end{tabular}

Fonte: Elaboração própria com base nos resultados do modelo de insumo-produto empregado na pesquisa.

diretamente o recurso, acaba por causar um impacto aos seus próprios setores de forma majoritariamente direta, diferente das outras regiões.

Do total do valor de produção gerado em Santa Catarina no Cenário A, R\$ 149,6 milhões são gerados de forma direta (Tabela 8) e R\$ 29,7 milhões, de forma indireta (Tabela 9). A soma é R\$ 179,3 milhões, como consta no início da seção. O impacto sobre o valor da produção setorial se difere entre o Cenário A e B, muito devido à agricultura - todas as regiões apresentam maior participação de suas respectivas agriculturas. Outra mudança importante é a maior distribuição dos impactos entre os demais estados brasileiros, o que não fere a hipótese de maior desenvolvimento local devido ao fato de que os impactos no estado aumentam, mesmo com menor participação no produto total.

Quanto aos efeitos diretos e indiretos do Cenário B, a produção total é de $\mathrm{R} \$ 202,6$ milhões. Os efeitos diretos na economia participam com R\$ 159,5 milhões e, os indiretos, com R\$ 43,1 milhões. O Cenário B tem R\$13,3 milhões a mais de efeitos indiretos em relação ao Cenário A e um efeito multiplicador maior. Quando se observa o Brasil, a agricultura passa a apresentar valor de produção do Cenário B 130\% maior em relação ao Cenário A; a pecuária é $86 \%$ maior e, alimentos e bebidas, $88 \%$ maior. O comércio apresenta quedas, de $26 \%$ e $69 \%$, respectivamente.

\section{Considerações finais}

A análise sobre o Programa Nacional de Alimentação Escolar (PNAE) em Santa Catarina partiu, por um lado, de entrevistas cujo objetivo foi avaliar os efeitos da qualidade da operacionalização do PNAE sobre a agricultura familiar em relação ao fornecimento da alimentação escolar. Por outro, a matriz insumo-produto propiciou o dimensionamento do impacto socioeconômico das compras realizadas junto a esse setor. A realização da pesquisa a campo evidenciou três pontos de aprimoramento da operacionalização do PNAE. 
O primeiro ponto trata do comprometimento dos órgãos executores do PNAE em dispor de corpo técnico e estrutura para promover a aquisição de gêneros e o estreitamento das relações com os fornecedores da agricultura familiar. Essa disposição inclui uma série de ações como a divulgação das chamadas públicas de compras de produtos da agricultura familiar, o apoio e incentivo aos nutricionistas e demais responsáveis diretos pela gestão e o contato com agricultores e suas organizações com suporte direto ao planejamento e execução da produção e viabilidade das entregas dos alimentos nas escolas.

O segundo ponto contempla o desenvolvimento de arranjos conjuntos que promovam a organização dos agricultores, a produção e a logística de distribuição de seus produtos. Em Santa Catarina existem órgãos de suporte ao agricultor, como a Empresa de Pesquisa e Extensão Rural de Santa Catarina (Epagri), a Secretaria da Agricultura de Estado e as secretarias municipais de agricultura, que poderiam ser elementos dinamizadores da política.

O terceiro ponto de destaque se refere à organização entre agricultores promovendo a superação do entrave de escala que coloca limitações para o suprimento contínuo e regular dos gêneros necessários para o abastecimento dos estudantes. Como exemplo de estruturas de uso comum, podem ser apontados os entrepostos utilizados para facilitar a logística dos produtos, as estruturas de processamento dos alimentos, os pontos de venda independentes, a abertura de outros canais de comercialização, a administração compartilhada, o local para reunião e troca de informações, entre outros.

A análise socioeconômica feita a partir da matriz de insumo-produto permitiu observar que as compras diretas da agricultura familiar, em comparação com compras via comércio, resultam em três mudanças com impacto positivo: maior geração de empregos; aumento da parcela do recurso destinado para a remuneração do trabalho e aumento de efeitos indiretos na movimentação econômica. Porém, a mesma comparação demonstra que compras diretas da agricultura familiar possuem resultados que poderiam ser considerados negativos, como a contabilização de um PIB menor, vazamentos da movimentação econômica para fora do estado de Santa Catarina e diminuição da remuneração de capital.

Os resultados demonstram que é bastante positivo o redirecionamento do recurso das compras de alimentos para as escolas em direção à agricultura. Esses recursos impulsionam a movimentação econômica nos locais de produção, incidindo fortemente sobre o emprego e a remuneração do trabalho. A eliminação de intermediários gera incentivos à produção local, circulação de recursos nos municípios, diversificação da produção e ao surgimento de pequenas cooperativas agroindustriais.

Pode-se afirmar que os aspectos negativos são superados pelos efeitos positivos. Em casos como esse, a maior movimentação econômica pode ser considerada mais relevante do que o PIB e a parcela de remuneração de capital quando o intuito é a distribuição de renda. Da mesma maneira, a maior dispersão dos recursos para outros estados, em detrimento de permanecer em Santa Catarina, deve ser analisada de forma dinâmica, pois, igualmente, a economia catarinense será afetada pelos desdobramentos das compras institucionais dos demais estados brasileiros. Nesse particular, parece claro que a agricultura familiar catarinense pode suprir a demanda de mercados institucionais de outros estados, tendo em vista a importância da sua estrutura produtiva familiar.

Foi possível identificar, ao longo do artigo, o potencial de transformação de compras institucionais em dinamizar as economias locais a partir do impulso aos agricultores familiares. Portanto, pode-se esperar que a ampliação da dimensão de compras institucionais para além dos $30 \%$ estabelecidos pela lei amplie também resultados positivos da geração de renda, diversificação da produção, melhorias nas propriedades e avanço organizacional entre agricultores, dinâmica que é corroborada pela análise de insumo-produto. O incentivo via renda não é necessariamente suficiente para promover a permanência do agricultor no campo, porém se constitui um apoio relevante.

Vale mencionar, entretanto, que a pesquisa qualitativa apresenta limitações, ainda que sua abrangência tenha permitido investigar um número representativo de municípios catarinenses. Os entrevistados, mesmo sendo representantes de agricultores, entidades executoras e órgãos de apoio ao agricultor, podem não ter a apreensão fidedigna da realidade local. Além disto, particularidades de locais não visitados podem ter restringido a análise. Já a pesquisa quantitativa, baseada na análise de insumo-produto, dado seu caráter estático, impede a projeção em detalhe dos impactos decorrentes da mudança de cenário. No entanto, apesar das limitações, os resultados permitem avaliar, com razoável aproximação, os efeitos da introdução das compras diretas de alimentos para os escolares. 


\section{Referências}

Baccarin, J. G., Triches, R. M., Teo, C. R. P. A., \& Silva, D. B. P. (2017). Indicadores de avaliação das compras da agricultura familiar para alimentação escolar no Paraná, Santa Catarina e São Paulo. Revista de Economia e Sociologia Rural, 55(1), 103-122.

Belik, W., \& Fornazier, A. (2016). Políticas públicas e a construção de novos mercados para a agricultura familiar: analisando o caso da alimentação escolar no município de São Paulo. Raízes, 36(2), 70-81.

Brasil. (2003, julho 2). Lei no 10.696, de 2 de julho de 2003. Dispõe sobre a repactuação e o alongamento de dívidas oriundas de operações de crédito rural, e dá outras providências. Diário Oficial [da] República Federativa do Brasil, Brasília.

Brasil. (2006, julho 25). Lei no 11.326 , de 24 de julho de 2006. Estabelece as diretrizes para a formulação da Política Nacional da Agricultura Familiar e Empreendimentos Familiares Rurais. Diário Oficial [da] República Federativa do Brasil, Brasília.

Brasil. (2015, junho 23). Decreto no 8.473, de 22 de junho de 2015. Estabelece, no âmbito da Administração Pública federal, o percentual mínimo destinado à aquisição de gêneros alimentícios de agricultores familiares e suas organizações, empreendedores familiares rurais e demais beneficiários da Lei no 11.326, de 24 de julho de 2006, e dá outras providências. Diário Oficial [da] República Federativa do Brasil, Brasília.

Bussab, W. O., \& Morettin, P. A. (2004). Estatística básica (5. ed.). São Paulo: Saraiva.

Corá, M. A. J., \& Belik, W. (2012). Projeto Nutre SP: análise da inclusão da agricultura familiar na alimentação escolar no estado de São Paulo. São Paulo: Instituto Via Pública.

Costa, B. A. L., Amorim Junior, P. C. G., \& Silva, M. G. (2015). As cooperativas de agricultura familiar e o mercado de compras governamentais em Minas Gerais. Revista de Economia e Sociologia Rural, 53(1), 109-126.

Estevan, D. O., \& Mior, L. C. (Org.). (2014). Inovações na Agricultura Familiar: as cooperativas descentralizadas em Santa Catarina. Florianópolis: Insular.

Food and Agriculture Organization - FAO. (2014). International year of family farming. In Proceedings of the $38^{\circ}$ Conference. Rome: FAO.

Fornazier, A. (2014). Inserção de produtores rurais familiares de regiões com baixa dinâmica econômica para o mercado da alimentação escolar (Tese de doutorado). Universidade Estadual de Campinas, Campinas.

Friedmann, H. (2000). Uma economia mundial de alimentos sustentável. In W. Belik \& Maluf, R. S. (Eds.), Abastecimento e Segurança Alimentar. Campinas: Unicamp.
Fundo Nacional de Desenvolvimento da Educação FNDE. (2017). Programa Nacional de Alimentação Escolar. Recuperado em 26 de julho de 2017, de http: / / www. fnde.gov.br/programas / alimentacao-escolar

Grisa, C., \& Schneider, C. G. (2015). Três gerações de políticas públicas para a agricultura familiar e formas de interação entre sociedade e estado no Brasil. Revista de Economia e Sociologia Rural, 52(1), S125-S146.

Guilhoto, J. J. M. (2011). Input-output analysis: theory and foundations (75 p.). USA: Munich Personal RePEc Archive.

Guilhoto, J. J. M., \& Sesso Filho, U. A. (2010). Estimação da matriz insumo-produto utilizando dados preliminares das contas nacionais : aplicação e análise de indicadores econômicos para o Brasil em 2005. Economia E Tecnologia, $23,53-62$.

Guilhoto, J. J. M., Ichihara, S. M., Silveira, F. G., Diniz, B. P. C., Azzoni, C. R., \& Moreira, G. R. C. (2007). A importância da agricultura familiar no Brasil e em seus estados. In Anais do $35^{\circ}$ Encontro Nacional de Economia. Recife: Venaber.

Instituto Brasileiro de Geografia e Estatística - IBGE. (2006). Censo Agropecuário 2006. Rio de Janeiro: IBGE.

Instituto Brasileiro de Geografia e Estatística - IBGE. (2010). Censo Demográfico 2010. Rio de Janeiro: IBGE.

Mattei, L. (2006). Estudos de impactos do PAA em municípios selecionados de Santa Catarina. Florianópolis: FAOFUBRA/UNB. Relatório de pesquisa para convênio FAO-ULBRA/UNB.

Mcmichael, P. (2009). A food regime genealogy. The Journal of Peasant Studies, 36(1), 139-169.

Miller, R. E., \& Blair, P. D. (2009). Input - output analysis: foundations and extensions (pp. 784). Cambridge: Cambridge University Press.

Mossmann, M. P., Teo, C. R. P. A., Busato, M. A., \& Triches, M. R. (2017). Interface between family farming and school feeding: barriers and coping mechanisms from the perspective of different social actors in Southern Brazil. Revista de Economia e Sociologia Rural, 55, (2), 325-342.

Programa das Nações Unidas para o Desenvolvimento - PNUD. (2015). Atlas do Desenvolvimento Humano no Brasil. Recuperado em 1 de agosto de 2015, de http: / / www.atlasbrasil.org.br

Santa Catarina. Secretaria de Estado da Educação de Santa Catarina. (2013). Relatório Agricultura Familiar 2012. Florianópolis: Secretaria de Estado da Educação de Santa Catarina.

Schejtman, A., \& Berdegué, J. (2004). Rural territorial development (Documento de Trabajo, No. 4). Santiago: Programa Dinámicas Territoriales Rurales.

Schneider, S. (2010). Situando o desenvolvimento rural no Brasil: o contexto e as questões em debate. Revista de Economia Politica, 30(3), 511-531. 
Silva, A. P. F. (2012). Demanda e oferta de alimentos orgânicos da agricultura familiar para a alimentação escolar em municípios de Santa Catarina (Dissertação de mestrado). Universidade Federal de Santa Catarina, Florianópolis.

Silva, A. P. F., \& Sousa, A. A. (2013). Alimentos orgânicos da agricultura familiar no Programa Nacional de alimentação Escolar do Estado de Santa Catarina, Brasil. Revista de Nutrição, 26(6), 701-714.

Silverio, G. A., \& Sousa, A. A. (2014). Organic foods from family farms in the National School Food Program: Perspectives of social actors from Santa Catarina, Brazil. Revista de Nutrição, 27(3), 289-300.

Sonnino, R., Lozano Torres, C., \& Schneider, S. (2014). Reflexive governance for food security: The example of school feeding in Brazil. Journal of Rural Studies, 36, 1-12.

Triches, R. (2010). Reconectando a produção ao consumo: a aquisição de gêneros alimentícios da agricultura familiar para o Programa de Alimentação Escolar (Tese de doutorado). Universidade Federal do Rio Grande do Sul, Porto Alegre.

Universidade de São Paulo - USP, \& Núcleo de Economia Regional e Urbana - NEREUS. (2019). Matrizes de insumoproduto. Recuperado em 10 de junho de 2015, de http: / / www.usp.br/nereus $/$ ?fontes=dados-matrizes

Van Der Ploeg, J. D. (2008). Camponeses e "Impérios Alimentares": lutas por autonomia e sustentabilidade na era da globalização. Porto Alegre: UFRGS.

Van Der Ploeg, J. D. (2011). Trajetórias do desenvolvimento rural: pesquisa comparativa internacional. Sociologias, 13, 114-140.

Wilkinson, J. (2008). Mercados, redes e valores: o novo mundo da agricultura familiar. Porto Alegre: UFRGS.

World Bank. (2008). Relatório sobre o Desenvolvimento Mundial de Agricultura para o Desenvolvimento. Washington: World Bank. 